ENTREVISTA

\title{
BASE NACIONAL COMUM CURRICULAR
}

Os desafios para a implementação da Base Nacional Comum Curricular (BNCC) e a expectativa de que ela diminua as desigualdades educacionais estão em debate nesta entrevista exclusiva com um dos relatores do Parecer que levou à sua instituição como norma para a Educação Básica de todo o País.

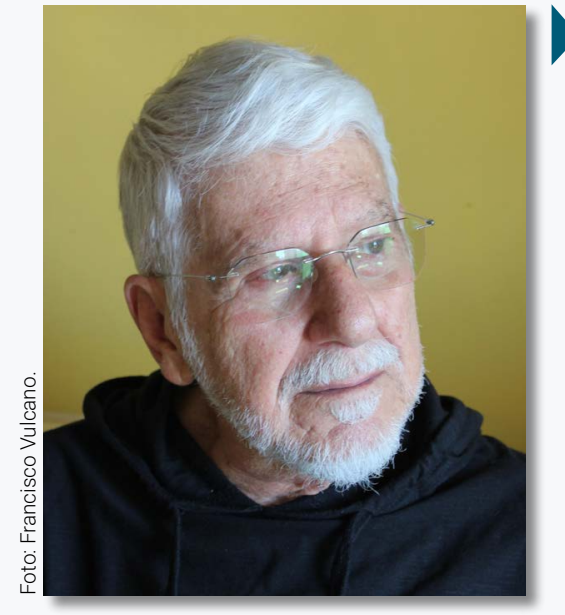

Bahij Amin Aur

Consultor em Educação, com trabalhos para instituições de Educação Básica, Profissional e Superior, públicas e privadas, incluindo a Organização das Nações Unidas para a Educação, a Ciência e a Cultura (UNESCO), Conselho Nacional de Educação (CNE), Ministérios da Educação e da Cultura, e Secretarias de Educação. Foi Diretor Regional do Senac de São Paulo. Integrou o Conselho Estadual de Educação de São Paulo e, atualmente, o Conselho Municipal de Educação de São Paulo. Membro honorário da Academia Paulista de Educação.

E-mail:aminaur@uol.com.br

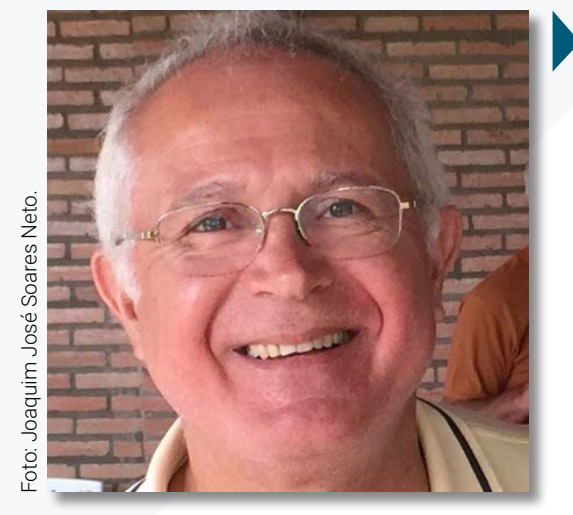

Joaquim José Soares Neto

Graduado em Física e professor titular da Universidade de Brasília, fez doutorado na Aarhus University, na Dinamarca, e pós-doutorado no California Institute of Technology, nos Estados Unidos. É membro da Comissão Nacional de Avaliação da Educação Superior (Conaes). Integra o conselho científico da Associação Brasileira de Avaliação Educacional. Foi presidente do Instituto Nacional de Estudos e Pesquisas Educacionais Anísio Teixeira e tem trabalhos publicados nas áreas de avaliação educacional e de física teórica. Há mais de 15 anos, envolve-se em pesquisas relacionadas à avaliação educacional. E-mail: jjsoaresneto@gmail.com 
BAA- Como correlator do Parecer que instituiu a implantação da Base Nacional Comum Curricular, como vê sua relevância para a melhoria da qualidade da Educação?

JJSN - O Brasil é uma federação. No que diz respeito à educação pública, os Estados e Municípios têm autonomia em relação ao currículo escolar. A BNCC vem para garantir que, independentemente da escola em que um aluno estude, ele tenha o direito a ter acesso a uma Base Curricular que seja comum a todos os outros alunos brasileiros. Isto por si só tem uma grande importância. A melhoria da qualidade depende muito do processo de implementação da BNCC. Na implementação, é fundamental levar em consideração os seguintes pontos: capacitação dos professores; investimento em infraestrutura das escolas; preparação dos materiais; e reestruturação das avaliações educacionais.

BAA- As extremas desigualdades no campo educacional em nosso País podem efetivamente ser reduzidas, tendo como instrumento a BNCC?

JJSN - Sim, elas podem ser efetivamente reduzidas. A BNCC deve se tornar um importante instrumento para a redução das desigualdades educacionais, pois a partir de agora, todos os alunos da educação infantil e do ensino fundamental terão uma Base Curricular comum.

BAA- Como foi o processo de elaboração do Parecer que instituiu a implantação da BNCC? Ao ser designado um dos seus relatores, concebeu sua elaboração partindo de um plano inicial ou a partir das Audiências Públicas promovidas pelo Conselho Nacional de Educação?

JJSN - No processo de construção do Parecer, partimos de uma estrutura inicial, que foi crescendo e ganhando corpo durante o ano de 2017. As contribuições vindas das Audiências Públicas e das discussões internas no próprio CNE foram sendo incorporadas gradativamente.

BAA- A realização destas Audiências revelou-se útil para a formulação do Parecer?

JJSN - As Audiências Públicas, juntamente com as contribuições vindas por meio de documentos protocolados no CNE, foram essenciais para a construção do documento final. A ampla maioria das sugestões e propostas foram incorporadas ao documento final da BNCC.

BAA- Como eram dois os relatores, como ambos trabalharam para chegar a um Parecer conjunto?

JJSN - O trabalho foi exaustivo e exigiu uma grande capacidade de negociação dos relatores. No final, o documento resultante foi bastante satisfatório e foi aprovado por ampla maioria do Pleno do Conselho Nacional de Educação. Recentemente, fiz uma nova leitura do documento final e sinto-me feliz com o trabalho realizado. 
BAA-A formação inicial de professores, sabidamente tem recebido críticas severas, sobretudo pela sua inadequação com a realidade do trabalho escolar. Como vê o papel da BNCC na solução dessa situação?

JJSN - A partir da aprovação da BNCC pelo CNE e sua homologação por parte do Ministro da Educação, teve início o processo de implementação desta. Este processo exigirá um enorme esforço relacionado à formação inicial dos nossos professores de educação básica. O primeiro passo será a reformulação dos currículos dos cursos de licenciatura.

\section{BAA- A BNCC tem visão focada na Educação de Jovens e Adultos?}

JJSN - A BNCC está focada na educação como um todo, incluindo a de Jovens e Adultos.

\section{BAA- A Educação Integral terá, a seu ver, possibilidades de ser efetivada?}

JJSN - A educação integral deve ser buscada de forma sistemática e sustentável. Devemos prestar muita atenção em como possibilitar a educação integral para aqueles alunos que frequentam escolas de pequeno porte e, em especial, aquelas em lugares longínquos. Em geral, o nível socioeconômico desses alunos é mais baixo e as escolas deles tendem a ter a infraestrutura mais frágil. Além do mais, seus desempenhos na prova Brasil também tendem a ser menores na média que os dos alunos que frequentam escolas maiores e em áreas urbanas. Digo isto porque se a educação integral for oferecida apenas a alunos em escolas urbanas e de maior porte, podemos agravar a desigualdade.

BAA-Como as etapas da Educação Infantil e do Ensino Fundamental são atribuições dos Municípios, você considera que a BNCC poderá dar uma dimensão nacional e não apenas local ao processo educativo?

JJSN- É fundamental que evitemos que isto aconteça. Devemos ter em mente o tempo todo que a BNCC foi construída como instrumento para a superação da grande desigualdade educacional do País.

\section{BAA- Que medidas você considera prioritárias para o sucesso da implementação da BNCC?}

JJSN - Várias medidas são necessárias: planejamento para ações a curto, médio e longo prazo, sem mudança de rumo nos momentos de mudanças de governos, tanto no âmbito da União quanto de estados e municípios; articulação entre a União, estados e municípios; capacitação inicial e continuada de professores; melhoria das condições de trabalhos dos professores, o que significa melhoria das carreiras e salários; investimentos em materiais e metodologias; e investimento em infraestrutura das escolas. Enfim, tudo isto depende muito de um orçamento adequado e bem-gerido. 